\title{
Apropiaciones territoriales y transformaciones socio-espaciales del maritorio de Chiloé
}

\author{
Territorial appropriations and socio-spatial transformations \\ of the Maritory of Chiloé
}

\author{
Apropriações territoriais e transformações socioespaciais \\ do Maritorio do Chiloé
}

\author{
Néstor Italo Carrera \\ Licenciado en Trabajo Social, Magíster en Ciencias Sociales, Doctor en Ciencias Sociales en \\ Estudios Territoriales. Académico del Departamento de Ciencias Sociales y Humanidades, \\ Universidad de Aysén (Chile). \\ Email: nestor.carrera@uaysen.cl
}

\section{María Patricia Baeza}

Licenciada en Trabajo Social, Doctora en Políticas Públicas y Transformación Social. Académica del Departamento de Ciencias Sociales y Humanidades, Universidad de Aysén (Chile) Email: mpatricia.baeza@uaysen.cl

\section{Ricardo Andrés Villalobos}

Ingeniero Comercial.

Director Regional Fundación Superación Pobreza, Región de Aysén (Chile)

Email: ricardovillalobos@superacionpobreza.cl

\section{RESUMEN}

Nos interesa, desde el punto de vista de los estudios territoriales y las transformaciones socioespaciales, evidenciar discursivamente distintos modelos de apropiaciones territoriales en el maritorio de Chiloé, ubicado en el sur de Chile, las cuales han tatuado en su geografía, desde hace miles de años y hasta el presente, imaginarios, significaciones y temporalidades diferentes. En este contexto, buscamos; a) reflexionar en torno a los discursos asociados a transformaciones socioespaciales y apropiaciones territoriales del maritorio de Chiloé desde una perspectiva históricoantropológica; b) describir cuatro tipos de apropiaciones, en tanto representaciones culturales, históricas y sociales del territorio; c) dar énfasis a las prácticas de recolección y cultivo de recursos del mar, sus simbolizaciones, y en consecuencia, la producción social de sentidos en el territorio/ maritorio como práctica continua y sistemática desarrollada en distintos tiempos.

Palabras clave: apropiaciones territoriales, transformaciones socio-espaciales, maritorio de Chiloé 


\section{ABSTRACT}

We are interested, from the point of view of territorial studies and socio-spatial transformations, discursively demonstrate territorial appropriation models in the Chiloé maritory, located in southern Chile, which have left their mark on their geography, since thousands of years and until now, imaginary, different meanings and temporalities. In this context, we seek; a) Reflecting on the discourses associated with socio-spatial transformations and territorial appropriations of the Maritory of Chiloé from a historical-anthropological perspective; b) Describing four types of appropriations, as cultural, historical and social representations of the territory; c) Emphasizing the practices of collection and cultivation of sea resources, their symbolizations, and consequently, the social production of senses in the territory/ maritory as a continuous and systematic practice developed at different times.

Key words: territorial appropriations, socio-spatial transformations, maritory of Chiloé.

\section{RESUMO}

Estamos interessados, do ponto de vista dos estudos territoriais e das transformações socioespaciais, em demonstrar discursivamente modelos de apropriações territoriais do maritorio do Chiloé, localizada no sul do Chile, que tatuam sua geografia, por milhares de anos e até ao presente, imaginários, diferentes significados e temporalidades. Nesse contexto, procuramos; a) Refletir sobre os discursos associados às transformações socioespaciais e apropriações territoriais do Maritorio de Chiloé sob uma perspectiva histórico-antropológica; b) Descrever quatro tipos de apropriações, como representações culturais, históricas e sociais do território; c) Enfatizar as práticas de coleta e cultivo de recursos marinhos, suas simbolizações e, conseqüentemente, a produção social de sentidos no território como prática contínua e sistemática desenvolvida em diferentes momentos.

\section{Palavras-chave: Apropriações territoriais - Transformações socioespaciais - Maritorio do Chiloé.}

\section{Introducción}

Para su subsistencia y evolución, los grupos humanos han articulado prácticas utilitarias con lenguajes basados en sistemas de creencias y construcciones simbólicas complejas. Como consecuencia, han surgido diversas formas de apropiación territorial y transformaciones socioespaciales. El dominio del fuego y de las formas elementales de la naturaleza, entre el mythos y lógos, trazaron itinerarios y cotidianeidades que se desplegaron como nodos y redes en espacios físicos concretos, que, a su vez, fueron apropiados y simbolizados ideo-afectivamente siendo convertidos en territorios. El ser humano y la naturaleza, en tanto unidualidad (Morin, 1997), han interactuado co-determinándose y generando transformaciones mutuas en el tiempo, de tal forma, que la propia intervención humana ha generado nuevas condiciones socioambientales a las cuales adaptarse. La inter-retro-acción entre ambos, ha tejido en el plano psicológico del ser humano, trayectos de exploración, descubrimientos y ensoñaciones, mundos residuales y simbólicos basados en comunicaciones situadas contextual e históricamente. La relación cultura-naturaleza en el maritorio de Chiloé, se caracteriza por el desarrollo de múltiples estrategias cognitivas de apropiación, usos de espacios, construcción de relaciones de dominio y poder, particularmente, a través de formas de vivir y habitar que han logrado -en mayor o menor medida- fusionar lo teleológico con lo axiológico, la praxis con lo simbólico y lo espiritual. Su evolución y nuevas nomenclaturas, actualmente nos ha incorporado a un nuevo marco global basado en relaciones de poder, comunicación, seguridad y control. 
Éstas relaciones de poder, han articulado -de forma principalmente económica- lo global con lo local, generando procesos de homogeneización y crisis identitarias "glocales" sin precedentes en el archipiélago. Nos interesa, desde el punto de vista de los estudios territoriales y las transformaciones socio-espaciales, evidenciar y visibilizar discursivamente modelos de apropiaciones territoriales en el maritorio de Chiloé en Chile, las cuales han tatuado en su geografía, desde hace miles de años y hasta el presente, imaginarios, significaciones y temporalidades diferentes. En este contexto, buscamos; a) reflexionar en torno a los discursos asociados a transformaciones socio-espaciales y apropiaciones territoriales del maritorio de Chiloé desde una perspectiva histórico-antropológica; b) describir cuatro tipos de apropiaciones, en tanto representaciones culturales, históricas y sociales del territorio; c) dar énfasis a las prácticas de recolección y cultivo de recursos del mar, sus simbolizaciones, y en consecuencia, la producción social de sentidos en el territorio/ maritorio como práctica continua y sistemática desarrollada en distintos tiempos.

Anclada a una metodología cualitativa, diacrónica y descriptiva, el presente texto destaca la revisión y análisis de fuentes primarias y secundarias, estructuras discursivas situadas, etnografía y actividades de discusión grupal de expertos, y a partir de ello, configura un relato ordenando cronológicamente las cuatro formas de ocupación y transformación espacial.

Para un adecuado desarrollo, el texto se divide en tres apartados. Inicia exponiendo conceptos asociados a los estudios territoriales, para luego, continuar con la exposición de cuatro modelos de apropiaciones ancladas a un mismo espacio (pero en tres temporalidades diferentes) particularmente las apropiaciones simbólicocultural (pasado mediato), utilitaria-funcional (pasado inmediato), simbólico-funcional (presente) y racional-instrumental (presentefuturo). Finalmente, se desarrolla una exoducción orientada a articular las principales conclusiones y discutir las implicancias territoriales de las dinámicas de extracción de recursos en el marco cultural de la modernidad capitalista.

\section{Contextualización desde la perspectiva de los estudios territoriales y las transformaciones sociales}

Desde la perspectiva de los estudios territoriales, las apropiaciones y transformaciones del espacio -en el maritorio de Chiloé- por la actividad humana, constituyen dos dimensiones de una misma realidad, para ello, es relevante anclar el análisis desde el concepto y categoría teórico-metodológica de territorio. El territorio, (Giménez, 1996, 2004; Vergara, 2007, 2009; Llanos-Hernández, 2010; Ther, 2006, 2011; Aliste y Urquiza, 2010; Gurevich, 2005; Claval, 2002) es un espacio apropiado por un grupo social para asegurar su reproducción y la satisfacción de sus necesidades vitales, las cuales pueden ser materiales o simbólicas.

En dicho contexto, el territorio es una construcción social producida, regulada y protegida por las colectividades humanas. El espacio geográfico apropiado, simbolizado e ideo-afectivamente habitado, es donde las relaciones de poder se desenvuelven en procesos complejos que articulan cuestiones en apariencia distintas pero que pertenecen a un mismo campo de acción, como lo son las relaciones afectivas, los procesos de apego y la división del trabajo y su desarrollo. De acuerdo a Vergara (2007), parafraseando a Loinger, el territorio refiere a lugares, direcciones, universos sensibles, palpables, de miradas, de caricias del espíritu y del cuerpo, colores y olores, percepciones y sensaciones. El territorio es todo eso, y la territorialidad expresa las prácticas vivientes en y por los territorios. En este contexto, "el territorio es parte constitutiva, pero es, también, extraño, así como nosotros somos parte y, a la vez, extraños a él. Estamos en él y él está en nosotros bajo la forma de la identidad y de la diferencia, de lo mismo y de lo otro, como dimensión irreductible" (Vergara, 2007, p.33).

Nos interesa destacar bajo ésta concepción, que por un lado, el imaginario capitalista global se diferencia de otras formas de estructuración territorial más simples y localizadas porque en 
su centro ha instituido sistemas de dominación basados en el poder, el saber, el control y el uso y explotación de los entornos y su biodiversidad. Para ello, se ha anclado en la racionalidad científica, la cual -desplegada en todas las instituciones sociales- ha contribuido a la estratificación, clasificación y cosificación del propio sujeto humano, y a su vez, sustituido sus sistemas de creencias anteriores por la centralidad del capital. Por otro lado, los imaginarios locales se han configurado a partir de temporalidades y saberes basados en formas otras de significación y construcción de sentidos. Si bien hoy la localidad contiene lo global y viceversa, antiguamente en el archipiélago de Chiloé hubo culturas cuyo imaginario subyacía a un marco holístico, no existiendo, en y entre ellos, distinciones claras, tampoco entre las formas de vida, ni entre éstas y sus entornos, en consecuencia, la producción de sus discursos, sentidos, representaciones comunitarias y relaciones ideo-afectivas, orbitaban en torno a la integración e inclusión territorial.

"En tiempos de globalización, los estudios sobre el territorio comúnmente discuten cuestiones relacionadas a la transformación del espacio físico a consecuencia del impacto de los fenómenos promovidos globalmente como son la internacionalización de la economía, pero muy poco o nada se ha dicho acerca de cómo el proceso de globalización impacta, afecta, metamorfosea al tiempo en las territorialidades de los espacios locales". (Ther, 2006, p.108).

\section{Apropiaciones territoriales y transformaciones socio-espaciales del maritorio de Chiloé}

\author{
Apropiación territorial simbólico- \\ cultural: Chiloé encantado, corrales \\ de pesca y ritual treputo
}

Un trabajo antropológico-arqueológico desarrollado en el archipiélago de Chiloé por los investigadores Munita, Álvarez y Ocampo, y que fue publicado en el Boletín de la Sociedad Chilena de Arqueología el año 2004, expone 22 sitios arqueológicos asociados a corrales de pesca, visibilizando una forma particular de apropiación territorial costera basada tanto en el mínimo impacto ambiental como en la simbolización sagrada de los espacios, prácticas que prevalecieron por más de seis mil años en el maritorio. Se denomina corrales de pesca a aquella tecnología de construcción orientada a la edificación de muros ubicados en el borde costero intermareal del archipiélago (o costa) y que mezclan piedras, varas y ramas para que actúen como trampa (contenedor) de peces. Al ser inundados los corrales de piedra por las mareas altas, y luego despejados al producirse las mareas bajas, los peces quedan al interior de los corrales facilitando su caza, recolección y procesamiento. Para los autores, el conocimiento directo del entorno, de sus recursos disponibles, de los ciclos de las mareas y de la conducta de la fauna ictiológica, son necesarios (sino vitales) para la construcción adecuada de los corrales de pesca. Dichas estructuras, representan la memoria de pueblos antiguos y fueron expresión de formas de vivir y habitar el territorio a partir de un modelo de intervención del ambiente basado en la subsistencia y las economías locales, a su vez, son expresión de la emergencia e institución de modelos societales costeros indígenas.

La visibilización de los corrales de pesca, desde el canal Beagle hasta la región de Magallanes, permite comprender la complejidad de las redes comunicativas y los modos de articulación histórica de las formas de apropiación del espacio costero. Se ha documentado su uso tanto para grupos con un énfasis de subsistencia terrestre (huilliche o williche) "como para pueblos canoeros, cazadores-recolectores marítimos como chonos, kawéshkar, yámanas" (Munita, et al., 2004, p.62). La investigación, da cuenta de que, en el siglo XVII, el padre Diego de Torres, se refiere al uso de los corrales de pesca por parte de los chono describiéndolos como corrales de ramas espesas o de piedra que suelen hacer en las mismas ensenadas. No obstante, si bien dicha técnica subyace a prácticas de pueblos locales, los españoles fueron quienes mejor provecho obtuvieron de ellas. 
Posteriormente, durante el siglo XVIII, la gran abundancia y facilidad en la explotación de los recursos pesqueros, gracias a la técnica de corrales, permite el desarrollo de un rubro de exportación a otras colonias hispanas en América.

"Cada año se enviaban cantidades de pescado ahumado y sardinas saladas. La extracción de estos recursos se efectuaba principalmente por medio de corrales. Estos eran estacas puestas en las bocas de las ensenadas que, al llenarse de agua con la marea creciente, dejaban retenidos a los peces en la vaciante. A esta labor dedicábanse especialmente los indígenas" (Olguín, 1971, p.51).

En el archipiélago y maritorio de Chiloé, el uso de corrales de pesca ha sido registrado y asociado históricamente a grupos huilliche y chono, también se ha vinculado a la sociedad mestiza chilota que hizo apropiación de dichos espacios, no obstante, en ambos casos, destaca siempre el aspecto étnico-cultural. El uso de los corrales de pesca, venía acompañado de diversos rituales y prácticas simbólicas, entre ellas, destacamos el Treputo.

"La ceremonia de castigar las aguas con ciertas ramas y bendecir el corral de varas trenzadas, era llamado "Treputo" o "Chepulo" en la pronunciación castiza. Hasta hace unas décadas todavía se practicaba. El equivalente al agua bendita era llamado ámbar y se depositaba en el corral de cerco para atraer buena pesca. Don Alfredo Nancuante, de Calen, nos contaba que el ámbar era un compuesto de apio silvestre, malva olor, palo mayor o baldahuén, agua florida, queso y laurel" (Cárdenas \& Hall, 1989, p.94).

El Treputo (pronunciado como cheputo) "se asocia principalmente al uso de corrales de pesca (de varas trenzadas o rocas) e implicaba el uso de plantas aromáticas y algunos objetos que cobraban un sentido mágico en un rito en el que originalmente participaba una persona cuyo rol, semejante al de un chamán, era denominado Pougtén" (Álvarez, 2011, p.4). Cada vez que una de esas estructuras se veía malograda en la cantidad de peces que atrapaba, se ahumaban dichas plantas, preparando manojos con los cuales era azotado el corral. Al mismo tiempo, se dejaban en diferentes partes de la estructura objetos que fomentarían la productividad del mismo. El ritual, cuyo carácter cultural se hallaba distribuido en todo el archipiélago de Chiloé, con el tiempo, se ha reducido a la práctica de azotar ramas de chaumán en redes y espineles. La distribución de los corrales de pesca en los estuarios, refleja -en cierta medida-lo que fue la estructura socioeconómica y de poder de las comunidades locales, a su vez, evidencia vínculos, distribuciones y lógicas sedentarias y nómadas. Quienes no tenían alternativas de beneficiarse de los corrales, debían esperar que algún propietario falleciese, y a partir de ello, acceder a través de negociaciones basadas en lazos familiares. Otra opción, era ser considerados "mirones o collis", rol que implicaba ir a los corrales en espera de que los propietarios le regalasen pescado sobrante. Los autores, identifican la participación de distintos actores en los procesos rituales, entre ellos, del curioso.

"Cada corral contrataba los servicios de un "curioso" (rol similar al de un chamán), quien conocía los poderes mágicos de ciertos objetos, y más importante aún, los procedimientos y palabras exclusivas para cada elemento a usar. Al inicio de cada temporada de pesca este curioso azotaba el corral con ramas de laurel, canelo, palotaique, y/o chaumán, además de emplear lagartijas amarradas y otros objetos denominados ámbar, todo se aplastaba con una piedra en el lugar. El objetivo de todo este procedimiento era proteger al corral de los males lanzados por otro curiosos (...), también protegerlos de la nefasta acción de animales mágicos como el cerdo-culebra cuchivilú, y también para atraer a los peces" (Munita, et al., 2004, p.64)

Actualmente, existen corrales de pesca activos y en uso, particularmente en Isla Añihué, Isla Mechuque, Isla Butachauques en Quemchi, Isla Apiao y uno en Isla Cahuach en Quinchao. Los corrales de pesca son reconocidos por las comunidades huilliche que habitan Chiloé 
como elementos identitarios y propios del patrimonio cultural del archipiélago, sin embargo, la mayor parte de los corrales en uso actual están edificados de varas trenzadas, complementando la estructura con mallas plásticas de salmoneras, trozos de redes, llantas de neumático y cualquier otro elemento que permita reforzar la estructura.

La investigación destaca, en el contexto del ritual en torno a los corrales, el uso de piedras llamadas quepuca, se trata de piedras mágicas vivas al igual que las plantas y los animales, con espíritu propio, y que permitían fertilizar las siembras (raspando su superficie sobre ellas) y el ganado (raspando su superficie sobre los abrevaderos). Su mantención estaba a cargo de mujeres traspasándose su propiedad de madre a hija y abuela a nieta. Para encontrarlas, era necesario ir a los ríos donde se encontraba una quepuca madre que paría quepucas.

"Quienes se dedicaban específicamente a practicar estos ritos recibían el nombre de «chaumaneadores». En estos ritos eran usadas principalmente piedras de diverso origen. Las más importantes eran las quepucas o capucas, unas piedras sílices, porosas, que se encontraban en los ríos. Había quepucas machos y hembras, las cuales se frotaban sobre las papas antes de ser sembradas. Cuando la siembra comenzaba a producir, se realizaba un segundo rito consistente en quemar las flores del papal antes de que saliera el sol, en honor de las quepucas (...) Para que no se agotara su poder, las quepucas debían mantenerse lejos de las miradas de los extraños, ocultas por el «curioso o encantador- en algún lugar secreto. Las piedras millahuillín o millaullín eran piedras calizas, similares a las quepucas, y también se encontraban en los ríos. Debían ser frotadas sobre el agua que luego sería regada sobre las papas que se iban a sembrar, pues aumentaban la producción. Con este mismo fin, se podía utilizar también una mezcla de mariscos molidos y polvo de quepucas y millahuillín. Las piriman, por su parte, eran piedras magnéticas que tenían el poder de aumentar la fertilidad de las siembras, los árboles y especialmente de las ovejas" (Álvarez, 2011, citando a Rojas, 2002, p.110).

En Chiloé, las culturas generaban sus propias formas de simbolizar sus prácticas, y todo ello, menguó con la irrupción del proceso colonizador en América del norte y del sur. Morris Berman (1987) -en un contexto más global- en su libro El reencantamiento del mundo, señalaba que la visión del mundo que predominó en occidente hasta la víspera de la revolución científica, fue la de un mundo encantado. Las rocas, los árboles, los ríos y las nubes eran contemplados como algo maravilloso y con vida, y los seres humanos se sentían a sus anchas en este ambiente. El cosmos, era un lugar de pertenencia y de correspondencia. Un miembro de este cosmos participaba directamente en su drama, no era un observador alienado. Su destino personal estaba ligado al del cosmos y es esta relación la que daba significado a su vida. Este tipo de conciencia, o como denomina él, conciencia participativa, involucra una coalición o identificación con el ambiente, habla o refiere a una totalidad psíquica que hace mucho ha desaparecido de escena.

\section{Apropiación territorial utilitario- funcional: Chiloé desencantado, la perspectiva eurocéntrica y geopolítica de la colonización del archipiélago}

El Archipiélago de Chiloé, desde el discurso occidental, es la segunda isla más grande de Sudamérica. Conocida por haber sido la tierra ancestral de los pueblos williche, chono y cunco, es un territorio de particular interés para los cientistas sociales e historiadores dado que durante las últimas tres décadas se han desarrollado de forma acelerada y sistemática significativas transformaciones ambientales, culturales, económicas y geopolíticas. Su historia ha sido registrada y estudiada por diversos autores (Urbina, 1983, 1998; Cárdenas \& Hall, 1985; Hanisch, 1982). En la actualidad, el mar interior de Chiloé está integrado por los 
Golfos de Ancud, del Corcovado y del seno del Reloncaví. Este territorio/maritorio, que ha vivido continuas transformaciones desde hace siglos y cuya referencia histórica se inicia desde el año 1567 a través de la conquista española, queda ubicado en la región de Los Lagos, Chile, cuyas coordenadas son 42\%40'36"S 7359'36"O, a un poco más de mil kilómetros de distancia de la capital, Santiago de Chile. Su superficie ha sido calculada en $8.394 \mathrm{~km}^{2}$ con una longitud de 180 km y una población aproximada de 180.185 habitantes, no obstante, el territorio tiene una importante masa flotante producto de sus dinámicas económicas y de turismo.

Su mayor punto de conectividad se desarrolla a través del canal de Chacao en el sector de Pargua vía transbordadores comerciales -a un poco más de 70 kilómetros -hacia el oeste- de la capital regional Puerto Montt. Este lugar, se encontraba habitado desde antaño, y hasta el año 1567, mayoritariamente por bandas nómadas dedicadas a la caza, pesca y recolección costera, esto último testificado por numerosos conchales y corrales de pesca. En el caso de los chono, estos fueron invadidos y asimilados, en parte, por los huilliche provenientes del territorio continental al norte del canal de Chacao. Conforme a su patrón económico y nivel de estructura social, los cunco han sido calificados como pescadores y horticultores agrupados en tribus sedentarias. Las actividades agrícolas principales ejercidas por ellos, consistían en cultivos de papa, el frijol y la quinoa (otros productos como semilla de trigo, cebada, avena, linaza, ajos, cebollas, arvejas, fueron introducidos por los españoles).

Por otro lado, para comunicarse entre las diversas islas y para sus viajes al continente, se servían de pequeñas embarcaciones denominadas bongos y dalcas. En este marco, se construirá la identidad de cada poblado apropiado por los españoles, su densidad poblacional y su relación con el medio, integrando en sus propias diferencias $y$ distinciones que derivaron en identidades locales. Los primeros reconocimientos por mar de la zona insular, fueron realizados por Alonso de Camargo en 1540 y cinco años más tarde por Francisco de Ulloa, quién en su expedición al Estrecho de Magallanes reconoció la costa de la isla y archipiélagos vecinos, siendo catalogado como su descubridor y primer explorador. En 1597, Martín Ruiz de Gamboa (fundador de la ciudad de Castro) anexó definitivamente el archipiélago a la Corona Española, Ilamándolo Nueva Galicia. La anexión del nuevo territorio, fue relativamente tranquila y sin situaciones bélicas significativas, debido a la escasa oposición presentada por los indígenas. Las dificultades en las comunicaciones y la dependencia establecida a través del Real Situado, generaron su tardía incorporación al Virreinato del Perú (1767).

Desde su conquista hasta 1598, el archipiélago se comportó como frontera abierta, esto es, como un espacio en proceso de colonización por parte de españoles, los cuales impulsaron nuevas conquistas hacia los territorios australes, lo que afianzaría la expansión y conquista del Estrecho de Magallanes. Su historia escrita más conocida por los hoy pobladores del territorio, se remonta a 1768 cuando el gobernador español don Carlos de Berenguer funda la ciudad de Ancud la cual cumplió en sus comienzos funciones de fortaleza para resguardar el tráfico por el Cabo de Hornos, esto dio a Ancud un prestigio y preponderancia que la convirtieron en la capital política y militar de este territorio en ese entonces.

La idea de conservar territorios estratégicos por parte de la corona española, dará pie a nuevos criterios de fundación, y que, en la planificación de las futuras ciudades, se manifestará desde un principio por su marcado origen defensivo, iniciándose en el siglo XVIII el período de las fortificaciones. El movimiento revolucionario que venía generándose en Chile, cuya primera manifestación fue el 18 de septiembre de 1810, pasó inadvertido en Chiloé por largo tiempo, ya que este territorio estaba padeciendo en grado superior del mismo problema de siglos anteriores, la incomunicación. Esta situación dejó al archipiélago con una economía altamente precarizada, el comercio limitó sus transacciones decayendo a un extremo lamentable por la escasez de naves con que transportar las maderas y productos agrícolas.

Bajo ese panorama, llegó el archipiélago a su independencia. El 30 de agosto de 1826, Chiloé formó una de las 8 provincias en que 
fue dividido el territorio nacional, involucrando los departamentos de Ancud (capital), Calbuco, Carelmapu, Castro, Chacao, Chonchi, Dalcahue, Lemuy, Quenacy Quinchao. Por Decreto Supremo del 28 de febrero de 1855, los 10 departamentos anteriores quedaron reducidos a 4: Ancud (capital), Castro, Quinchaoy Carelmapu. Posterior a 1960, con la construcción de la Carretera Panamericana que unía los principales puntos del país, la ciudad de Puerto Montt se constituye como un centro económico y comercial de relevancia nacional, rol que se conserva hasta nuestros días.

\section{Apropiación territorial simbólico- utilitaria: Chiloé alienado, el caso de los recolectores de orilla}

Una apropiación territorial simbólico-utilitaria, que articula lo simbólico (identitario) con lo funcional (estratégico), refiere a la forma en que un grupo o colectivo humano y sus integrantes viven, simbolizan y se apropian ideo-afectivamente del espacio, cargando con dinámicas productivas y/o de subsistencia el borde costero, tanto como parte de su identidad heredada como por la necesidad de adaptación a la realidad presente (global) del territorio, generando procesos de apego e integrando las racionalidades y prácticas propias del entorno y sus contextos.

No se trata sólo de conservar vestigios de símbolos o significados del pasado, sino imbricar, a partir de nuevas significaciones, lo tradicional con lo moderno, construyendo una nomenclatura virtuosa (o crítica) entre la memoria y el futuro, en el contexto de un imaginario (Castoriadis, 1983) global que permea lo local.

Entre algunas prácticas de apropiación simbólico-utilitaria, se encuentra el recolector de orilla, en tanto práctica y memoria heredada ancestralmente y vigente en el presente, al igual que los grupos indígenas de Norteamérica antes de América.

"Lo notable de esta memoria (...) es que se fundió con el canon de la historia occidental y el resultado final fue el surgimiento de un producto hibrido al que tuvieron que acudir los grupos indígenas sobrevivientes para reconstruir su memoria y preservar su identidad" (Farfán, 2009. P.145; en Valencia, G. 2009).

Hablamos de recolector de orilla, alguero o recolector apnea, cuando nos referimos a quienes realizan actividades de extracción, recolección o segado de recursos hidrobiológicos. En la actualidad, la identidad cultural ancestral que arrastra esta práctica se ve transformada por nuevas identidades, modos de hacer y discursos que se reapropian del borde costero y sus recursos, transformando fuertemente a herederos de los pueblos chono y cunco, grupos humanos que han sabido sortear la fusión de dos culturas distintas, pero que han sido asimilados -en su mayoría- por la cultura de occidente.

Según el Primer Censo Nacional de Pesca y Acuicultura (2008), un 16,7\% de los pescadores artesanales pertenecen a un pueblo indígena, un $15,8 \%$ son de origen mapuche, y el $21,6 \%$ de los recolectores de orilla pertenecen a alguno de los pueblos originarios de Chile. Las comunidades mapuche-lafkenche y mapuche-williche, se caracterizan por administrar colectivamente el espacio en base a normas tradicionales, más que por las leyes nacionales, siendo la recolección una actividad familiar y comunitaria.

Antes de ser incorporados en la ley, los recolectores de orilla no asociados, y las comunidades indígenas, estuvieron sin poder realizar sus actividades en esas franjas o bordes costeros reservadas a AMERBS (áreas de manejo y explotación de recursos bentónicos), restringiendo su zona de operación pesquera, siendo estos, territorios normados.

Actualmente, para efecto de quedar habilitados ante la ley y poder realizar actividades de pesca, las personas que desarrollan prácticas de extracción de recursos en el borde costero, deben estar inscritos en el Registro Nacional de Pescadores Artesanales (RPA), ello les permite participar en el Sistema de Régimen 
Artesanal de Extracción, en el Fondo de Fomento establecido, y a su vez, postular a áreas de manejo y explotación de recursos bentónicos.

El proceso administrativo de organización territorial del maritorio de Chiloé por parte del Estado, por un lado, ha sido considerado homogeneizante, en términos de proporcionar condiciones legales idénticas que permitan, en el contexto de hoy, extraer recursos hidrobiológicos y limitar las cantidades según especie y tamaño, independiente del aspecto cultural de los grupos humanos de pescadores artesanales. Esta falta de diferenciación cultural se instituye como instrumento de invisibilización de las diversidades locales.

Por otro lado, y de acuerdo a la percepción de recolectores locales indígenas de Chiloé, es un proceso de colonización continua, sistemática e instrumental, que deriva en la usurpación, asimilación y fragmentación de las identidades locales, racionalizándolas y convirtiéndolas al dogma de la nueva forma de administración burocrática e institucional, situación que se acentúa con la incorporación del modelo neoliberal en Chile en la década de los 80 y 90, acentuado la discriminación contra los pueblos originarios, y profundizándose en las últimas décadas, a excepción de la ley lafkenche (20.249, 2008).

"La doctrina de la tutela de los colonizadores europeos consideraba superiores a las naciones de Europa propugnando como un deber sagrado imponer su dominación y cultura a aquellos pueblos menos "civilizados", justificando así la apropiación de territorios que no eran suyos" (Zelada, S. \& Park, J., 2013, citando a RodríguezPiñero, 2004).

"En el ámbito marino, los habitantes del territorio saben los límites de cada comunidad tanto en el ámbito terrestre como en los sectores de playa. A diferencia de la tierra, los límites comunitarios en las playas se rigen por normas tradicionales y no por las leyes estatales, dichos límites son identificados por medio de marcas y elementos de la naturaleza y no cercos
[...] Las normas de manejo ancestral implican acuerdos orales, pactados entre las familias, que difícilmente pueden ser textualizados" (Zelada \& Park, 2013, p.54; citando a Castro, 2005).

La recolección de algas y de otras formas de vida se mantiene hasta el presente, es una práctica cultural asociada a la alimentación de comunidades mapuche -o williche- de Chiloé, los cuales se distinguían de otras porque "las comunidades más tradicionales se encuentran al interior de la isla y no en la costa misma" (Ruiz, 2003, P.23).

La práctica de recolección de orilla tiene relación con la extracción humana de recursos hidrobiológicos y depende de los distintos niveles de varamiento o encasillamiento de recursos en las orillas. Algunas especies pueden ser luche, algas, mariscos, entre otros. Posterior a su extracción, su venta se desarrolla en mercados locales, en su mayoría orientados al consumo familiar y abastecimiento de restaurantes. La extracción, se desarrolla dependiendo de las mareas y no requiere instrumentos sofisticados. Existen distinciones entre recolectores, existiendo dos configuraciones que difieren en sus técnicas: Los maneros y los pateros, y además ellas, una forma de buceo que conserva las técnicas del patero, pero incorpora tecnología moderna, a ésta práctica se le denomina buceo Hooka. Los Maneros, o extracción con manos, es una actividad desarrollada por personas de todos los grupos etarios. A veces, constituye un ritual familiar, en otras ocasiones, formas de subsistencia que responden a una situación económica que vive la familia.

Las organizaciones civiles asociadas al mar, incorporan dentro de sus espacios a personas que desarrollan esta práctica tanto por un concepto cultural como por elección de las personas. La extracción de los recursos que los maneros realizan, se caracteriza por situarse en la orilla de la playa y/o en el agua, hasta una profundidad que no implique apnea y que no supere el agua la altura de la cintura. Con sus manos, los recolectores ejecutan un movimiento que les permite abrir una cavidad en el agua, y al mismo tiempo que dan paladas contra el 
suelo marino, utilizan un quiñe, caracterizado por una argolla flexible y una red que lo envuelve y permite colectar los recursos extraídos en ella. Existen quiñes de distintos tamaños, los cuales pueden estar elaborados con materiales de mangueras o alambres, por lo general, el artefacto es colgado en la cintura facilitando recoger y conservar las especies extraídas. Tienen un sistema de cerrado en su abertura (argolla), la cual consiste en una pequeña cuerda que atraviesa en su parte superior la red. Al tirarla, esta cierra y evita que lo recolectado se pierda. Los pateros, son recolectores que trabajan particularmente en marea baja. Se desenvuelven entre la orilla y hasta donde el nivel del mar llega a sus hombros, lo que les permite usar los pies como herramienta de detección y como palanca para levantar los recursos y ser cogidos. Gracias a la suspensión transitoria de la respiración (apnea), al sumergirse y por el transcurso de unos minutos o segundos, acceden de forma directa con las manos a ciertos bancos de recursos, y con ello, optimizan los resultados, aumentando la cantidad de recursos extraídos y disminuyendo el tiempo de trabajo. El buceo hooka, es una práctica cuyas técnicas son idénticas a las del patero pero que incorpora tecnología moderna, principalmente, para sumergirse conectado a un motor de aire desde la orilla y trabajar hasta dos metros bajo el nivel del mar. Consiste en el uso de un traje de buceo, cinturones o mochilas de plomo (en la cintura y espalda), máscara-visor y un quiñe. Bajo el agua, su forma de extracción es utilizando los talones con los cuales hacen una cavidad de 40 a $50 \mathrm{~cm}$. de profundidad. Teniendo la cavidad en el suelo hecha, se arrodillan para recolectar. Otra técnica utilizada, es el arrastre, en la cual introducen en la cavidad la argolla de metal de forma vertical arrastrándola por el fondo para después levantar la argolla haciendo caer el recurso por la red.

Estas tres prácticas de recolección de orilla, diferenciadas por la incorporación de tecnologías, profundidad de inmersión, entre otras, constituye parte del acervo cultural e histórico del archipiélago y toman forma bajo distintas propuestas en el maritorio interior de Chiloé. Los sincretismos, apegos y referentes de pertenencia se encuentran fragmentados, y aun cuando persisten imágenes poéticas de una herencia cultural subalternizada, las nociones y discursos que constituyen sus representaciones sociales e imaginarios, siguen ancladas y legitimadas por su origen lafkenche.

\section{Apropiación territorial racional- instrumental: La acuicultura y la transformación socio-espacial del maritorio de Chiloé}

Una apropiación racional-instrumental o tecnocientífica en el contexto del maritorio de Chiloé, refiere a una forma específica (moderna) de racionalidad cuyos dispositivos instrumentales de poder subyacen a formas de conocimiento que estimulan la intervención, la modificación y la transformación (des)controlada de la naturaleza, a su vez, promueven la erradicación o invisibilización de sistemas de creencias otros (pre-existentes como los saberes de los pueblos originarios).

La razón instrumental, en tanto técnica apropiadora de los entes y las cosas, contribuye a la reducción/fragmentación del territorio a sus partes, y orienta sus propósitos desde las lógicas del mercado. Los conflictos socioecológicos en el Maritorio Interior de Chiloé en el 2007 y 2016, y cuya cobertura se extendió en parte importante del litoral de la región de Los Lagos, dio cuenta de que la trasformación sin mesura de la naturaleza por los sistemas culturales modernos ha llegado a un punto de incertidumbre respecto de sus efectos, donde la naturaleza modificada-intervenida (ambiente transformado) revierte dicho daño trayendo como consecuencia la destrucción (o riesgo de ello) de los sistemas culturales y el conjunto de prácticas que lo determinan, "la sociedad se pone en peligro a sí misma, en la medida en que produce efectos en el medio ambiente" (Luhmann, 2012, p.82).

Dichas transformaciones, se desarrollaron con más fuerza desde 1990 a partir del crecimiento exponencial de prácticas de apropiación costera para la acuicultura (salmonicultura). 
En el contexto de significativas y aceleradas transformaciones en los territorios locales, como consecuencia del proceso de modernización e introducción de distintos modelos de producción económica, los conflictos socioecológicos y crisis socioambientales emergieron, y su origen refirió a la incorporación de la racionalidad económica, "esta encrucijada civilizatoria es ante todo una crisis de la racionalidad de la modernidad y remite a un problema del conocimiento" (Leff, 2006, p.192).

En el desarrollo de la acuicultura en Chile, y particularmente en Chiloé, a través de una perspectiva histórico/antropológica, se pueden distinguir tres periodos importantes. De acuerdo a Martínez (2003) el primero, se sitúa entre 1850 y 1920 (gestión privada), que inició en Chile la etapa de introducción de especies acuícolas exóticas, como truchas, carpas y pejerreyes, para potenciar la pesca recreativa.

El segundo período (gestión estatal), entre 1921 y 1973, se caracterizó por los esfuerzos orientados a la introducción del salmón coho o plateado (Oncorhynchus kisutch) y por establecer actividades económicas comerciales, en esto último, el Instituto de Fomento Pesquero (IFOP) tuvo un rol destacado en cuanto a implantar en el país tecnologías extranjeras pioneras y necesarias para el cultivo de distintas especies acuícolas y traer a expertos internacionales para transmitir e instalar esos conocimientos especializados.

El tercer período (gestión industrial), comienza en 1974 y se extiende hasta el día de hoy, donde la actividad a nivel comercial se ha consolidado mediante una política económica de impulso a la gestión privada y apertura de los mercados internacionales, principalmente a través de los tratados de libre comercio. El aporte estatal, si bien se ha reducido ostensiblemente desde la perspectiva del empresariado, con el tiempo se ha ido concentrando en un apoyo indirecto a través de la apertura y entrega de fondos concursables para proyectos de investigación, desarrollo tecnológico y evaluaciones diagnósticas, entre otros.

A lo largo del camino, cada especie de cultivo ha tenido su propia historia y, en éste contexto, la salmonicultura se erige como una de las actividades más importantes en lo comercial. En 1995 se creó el Instituto Tecnológico del Salmón, Intesal, por iniciativa de la Asociación de productores del Salmón y Trucha de Chile A.G. -hoy SalmónChile- con el objetivo de aumentar la eficiencia productiva de la industria y preocuparse de los aspectos sanitario, medioambiental y de capacitación.

Sin embargo, ¿Qué vínculos existen entre la acuicultura, en tanto apropiación territorial racional-instrumental y los conflictos socioambientales del maritorio de Chiloé? Los efectos de la salmonicultura (Amtmann \& Blanco, 2001; Barton, 2010; Buschmann. \& Fortt, 2005; Bustos, 2012), ponen en evidencia que la contaminación de columnas de agua, deterioro de los suelos marinos, costas del mar interior y exterior de Chiloé, son el resultado de procesos alimenticios de los salmones que afectan la bioquímica del agua tras el abuso de antibióticos.

Dicha apropiación racional-instrumental o tecno-científica, da cuenta de la emergencia de enfermedades, bacterias resistentes, virus, anemias, mortandad de peces, crisis socioambientales sin precedentes. En lo social, migración de pescadores artesanales al rubro acuícola, cesantía y despidos masivos, mala calidad de empleos, deterioro de la salud física y mental de los trabajadores, a su vez, no cumple con las promesas de dejar la explotación de los recursos marinos por el cultivo, ser instrumento de lucha contra el hambre, producción masiva de alta calidad y a bajo costo, acceso local a los productos, ser una industria estable, etc.

La falta de protocolos, regulaciones y fines sociales tras la industria, evidencia que dicha forma de apropiación territorial, bajo el discurso de organizar la extracción de recursos, transformó los espacios marítimo costeros en función de los intereses económicos de empresas transnacionales, y en consecuencia, subalternizó a los actores y organizaciones locales bajo un marco que limitó sus actuaciones trayendo como consecuencia manifestaciones sociales y movilizaciones ciudadanas, que aunque 
mediáticas, sucumbieron a las relaciones de poder Estado-Empresas.

\section{Exoducción}

En el presente texto, hemos descrito y analizado cuatro apropiaciones territoriales diferenciadas tanto por sus temporalidades como por sus modos de vivir y habitar el maritorio de Chiloé, es decir, por sus actores, racionalidades y cosmovisiones.

Las transformaciones socio-espaciales dinamizadas por identidades, sistemas de creencias y prácticas, interpelan periodos históricos asociados con cambios significativos en contextos de pre y post colonización, y cuyos cambios, refieren a la aparición de diversos actores y racionalidades.

Desde el enfoque territorial, las apropiaciones simbólicas, utilitarias, simbólico-utilitarias y racional-instrumental, representan distintas estrategias cognitivas -de tiempos articulados linealmente- de las cuales emergen una pluralidad de imaginarios y construcciones sociales basadas en la relación cultura-naturaleza y entre la interacción de grupos humanos locales y procesos de colonización. Cada modelo de apropiación transforma el espacio a partir de procesos de significación en la que participan racionalidades, subjetividades y apegos en principio diferentes, y luego, entramados. En su conjunto, estos procesos de significación derivan en la construcción de discursos y apropiaciones situadas temporal y espacialmente, dotando de identidades transitorias y cambios constantes el devenir histórico local.

El sistemático desencantamiento del archipiélago ha instituido un modo racional de pensamiento que ha fragmentado y cosificado los espacios y personas incorporándolos en la trama global desde el enfoque economicista, ello ha conducido a la emergencia de crisis socioambientales e identitarias sin precedentes (2007-2016).

El archipiélago de Chiloé, en tanto territorio vivido, concebido y normado, evidencia el modo en que los imaginarios se superponen temporalmente a través de imbricaciones y tramas complejas (dialógicas y recursivas) como producto de procesos de interacción basados en relaciones de poder (saber-hacer).

La urgencia de alternativas a la racionalidad económica hegemónica como motor de transformación social se evidencia en las consecuencias del inadecuado uso de los conocimientos científicos (salmonicultura al alero de la racionalidad costo-beneficio).

Los distintos discursos-apropiaciones expuestos, contribuyen a comprender perspectivas a partir de las cuales se inscribe la historia en el imaginario colectivo isleño. Cuestionarlas, reflexionar sobre ellas y analizarlas, permite generar condiciones para el desarrollo de investigaciones y propuestas de articulación interdisciplinar orientadas a soluciones que promuevan la visibilización de la diversidad interna de los territorios.

En dicho contexto, y como atractores investigativos para futuras investigaciones $¿ \mathrm{De}$ qué otras formas, en tiempos contemporáneos, se expresan los procesos de sincretismo cultural en el archipiélago? ¿qué aprendizajes se obtienen de las experiencias de apropiación que han derivado en crisis identitarias y ambientales, $y$, cómo se expresa en la institución de gobernanzas adecuadas? ¿qué representaciones sociales, imaginarios y procesos de significación emergen con la incidencia de la tecnología en el marco de la globalización? ¿a cuáles transformaciones socioespaciales nos veremos enfrentados -en tanto maritorio- con la incorporación sistemática de la racionalidad turística en los planos económicos, políticos y sociales -dentro de los próximos años-? 


\section{Referencias}

Aliste, E. \& Urquiza, A. (2010). Medio ambiente y sociedad: Conceptos, metodologías y experiencias desde las ciencias sociales y humanas. RIL editores. ISBN: 978-956-284-727-8. Santiago, Chile.

Álvarez, R. (2011). Prácticas rituales asociadas a tierra y mar: quepucas y treputo. III Seminario "Chiloé: historia del contacto" 1, 2, 3 y 4 de junio de 2011. DIBAM.

Amtmann, C. \& G. Blanco. (2001). "Efectos de la salmonicultura en las economías campesinas de la Región de Los Lagos". Revista Austral de Ciencias Sociales, № 005, Valdivia, Chile.

Barton, J. (2010). La doble jerarquía del desarrollo económico y gobierno local en Chile: El caso de la salmonicultura y los municipios chilotes. EURE, Vol. 36, N 108, pp. 123-148.

Berman, M. (1987). El reencantamiento del mundo. Ed. Cuatro vientos. Santiago de Chile.

Buschmann, A. \& Fortt, A. (2005). Efectos ambientales de la acuicultura intensiva y alternativas para un desarrollo sustentable. Ambiente y Desarrollo, 21(3), 58-64.

Bustos, B. (2012). Brote del virus ISA: crisis ambiental y capacidad de la institucionalidad ambiental para manejar el conflicto. EURE, Vol. 38, Nº115. Septiembre, pp. 219-245.

Cárdenas, R. \& Hall, C. (1989). Manual de pensamiento mágico y la creencia popular. Editorial El Kultrún. Valdivia, Chile.

Castoriadis, C. (1983). La institución imaginaria de la sociedad. Vol. I. Tusquets Editores.

Claval, P. (2002). El enfoque cultural y las concepciones geográficas del espacio. Boletín de la A.G.E. $n^{\circ} 34$, pp. 21-39.

Gurevich, R. (2005). Sociedades y territorios en tiempos contemporáneos: una introducción a la enseñanza de la geografía. $7^{a}$ Ed. Fondo de Cultura Económica. Buenos Aires.

Hanisch, W. (1982). La Isla de Chiloé, Capitana de Rutas Australes. Academia superior de ciencias pedagógicas. Alfabeta Impresores. Santiago, Chile.

INE (2008). Censo Nacional de Pesca y Acuicultura. Instituto Nacional de Estadísticas. Gobierno de Chile.

Llanos-Hernández, L. (2010). El concepto del territorio y la investigación en las ciencias sociales. Agricultura, sociedad y desarrollo. Vol. 7, n³. Septiembre-Diciembre, pp. 207-220.

Leff, E. (2006). Complejidad Ambiental. Conferencia presentada en el 3er Seminario Bienal Internacional, Complejidad 2006. La Habana, Cuba, 9-12 de enero.

Legoupil, D. (2005). "Recolectores de moluscos Tempranos en el sureste de la isla de Chiloé: una primera mirada". Revista Magallania. Vol. 33: 51 - 61.

Luhmann, N. (2012). ¿Puede la sociedad moderna evitar los peligros ecológicos? Revista Argumentos, N² 25 (Mayo-Agosto) Disponible en: http://www.redalyc.org/. 
Martínez, S. (2003). Historia de la acuicultura. TechnoPress S.A. Editorial de AquaNoticias. $1^{\circ}$ ED. Directorio de Acuicultura y Pesca de Chile SalmónChile. Santiago, Chile.

Morín, E. (1997). La unidualidad del hombre. Gazeta de Antropología. N 13. Artículo 1. ISSN 0214-7564.

Munita, D. \& Álvarez, R \& Ocampo, C. (2004). "Corrales de piedra: pesca pasiva en la costa interior de Chiloé". Boletín de la Sociedad Chilena de Arqueología N³7: 61 - 74.

Ocampo, C., Rivas, P. (2004). "Poblamiento temprano de los extremos geográficos de los canales patagónicos: Chiloé e isla Navarino”. Revista Chungará. (Arica) V. 36.

Olguín, C. (1971). Instituciones políticas y administrativas de Chiloé en el siglo XVIII. Publicaciones del Seminario de Historia y Filosofía del Derecho de la Facultad de Ciencias Jurídicas y Sociales de la Universidad de Chile. Estudios de derecho Indiano. Editorial jurídica de Chile, Santiago, Chile.

Ruiz, C. (2003). La estructura ancestral de los mapuches: Las identidades territoriales, los Longko y los Consejos a través del tiempo. En Jorge Calbucura (ed.). Disponible en: http://www.mapuche. info/wps_pdf/Ruiz031100.pdf.

Selada, S. \& Park, J., (2013). Análisis crítico de la Ley Lafkenche (N²0.249). El complejo contexto ideológico, jurídico, administrativo y social que dificulta su aplicación. UNIVERSUM, N²8. Vol. 1. Universidad de Talca.

Ther, F. (2011). Configuraciones del tiempo en el Mar Interior de Chiloé. Desenvolvimento e Meio Ambiente, n. 23, p. 67-80, jan./jun. 2011. Editora UFPR.

_. (2006). Complejidad territorial y sustentabilidad: notas para una epistemología de los estudios territoriales. Horizontes Antropológicos, Porto Alegre, año 12, n. 25, p. 105-115, Brasil.

Urbina, R. (1983). La periferia meridional indiana. Chiloé en el siglo XVIII. Ediciones universitarias de Valparaíso, Universidad católica de Valparaíso.

_. (1998). Gobierno y sociedad en Chiloé colonial. Valparaíso, Chile. Universidad de Playa Ancha, Facultad de Humanidades, pp. 297. En http://www.memoriachilena.gob.cl/

Valencia, G. (2009). El tiempo en las ciencias sociales y las humanidades. Centro de Investigaciones Interdisciplinarias en Ciencias y Humanidades. UNAM. México. Colección Debate y Reflexión.

Vergara, N. (2009). Complejidad, espacio, tiempo e interpretación: Notas para una hermenéutica del territorio. ALPHA No 28 Julio, pp. 233-244.

_. (2007). Hombres y entornos: Notas para una metafísica del territorio. ALPHA, N² 25 diciembre, pp. 227-236. 